\title{
The use of electromagnetic data for short-term prediction of Vrancea (Romania) earthquakes: Preliminary data
}

\author{
B. D. Enescu, D. Enescu, and A. P. Constantin \\ National Institute for Earth Physics, P.O.Box MG-2, Bucharest-Magurele, 76900, Romania \\ (Received October 28, 1998; Revised February 21, 1999; Accepted April 19, 1999)
}

\begin{abstract}
Diagrams from electromagnetic data that were recorded at Muntele Roşu Observatory during the periods from December 1996 to January 1997, and December 1997 to September 1998 were plotted. The times when Vrancea earthquakes of magnitudes $M \geq 3.9$ occurred within these periods are marked on the diagrams.

The magnetic data prove that Vrancea earthquakes are preceded by magnetic perturbations that may be regarded as their short-term precursors. Some of these perturbations may also be regarded either as geomagnetic storms or as instrument effects.

Perturbations, which could likewise be seen as short-term precursors of Vrancea earthquakes, are also noticed in the electric records. Still, a number of electric data do cast a doubt on their forerunning nature.

Some suggestions are made in the end of the paper on how electromagnetic research should go ahead to be of use for Vrancea earthquake prediction.
\end{abstract}

\section{Introduction}

Earthquake prediction requires the use of not just seismological research but also other geophysical methods as well as various additional methods such as geochemical, geomorfological-geodesic, biological, etc.

The electromagnetic method is one of several geophysical methods that can be used for earthquake prediction.

The idea of applying the electromagnetic method in order to predict Vrancea strong $(M>7)$ earthquakes is supported by some encouraging results reported on an international level (Honkura et al., 1976; Gokhberg et al., 1982; Fraser-Smith, 1990; Yoshino, 1991; Ernst et al., 1993; Park et al., 1993; Varotsos et al., 1993; Johnston, 1997 etc). The problem is of special significance even for no other reason than this being the first attempt at using the electromagnetic method to predict the major dangerous Vrancea earthquakes. Therefore in 1996-1997 we took the initiative of effectively setting up two electromagnetic observatories (Muntele Roşu and Vrâncioaia-see Enescu et al., 1998) in the Vrancea seismogenic region or its proximity (Fig. 1).

Preliminary results based on Muntele Roşu electromagnetic records are given below. They refer to the period from December 1996 to September 1998, with one longer, 11month break in 1997, and three shorter ones. The reasons for the breaks and why Vrâncioaia records were not used are also presented below.

\section{Muntele Roşu Electromagnetic Observatory}

This location-Muntele Roşu-was picked in such a way as to ensure an optimum positioning with respect to Vrancea seismic area (Fig. 1).

Copy right $(\mathrm{c})$ The Society of Geomagnetism and Earth, Planetary and Space Science (SGEPSS); The Seismological Society of Japan; The Volcanological Society of Japan; The Geodetic Society of Japan; The Japanese Society for Planetary Sciences.
Moreover, this site was so chosen as to be distant from railroads and any other sources of noise in order to avoid disturbing signals. This electromagnetic observatory is structured as in Fig. 2, and consists of:

- a three-axis magnetic field sensor (fluxgate; $\pm 70 \mu \mathrm{T}$ measuring range), produced by "Bartington Instruments" (England)

- nonpolarizable electric sensors $(\mathrm{Cu}-\mathrm{Cu} \mathrm{SO}$, in caolin gel);

- a data logger-acquisition module (six channels, 24 bytes resolution, sample rate programmable), produced also by "Bartington Instruments".

- a computer for data storage and preliminary processing.

The three-axis magnetic field sensor is low-noise type, which accounts for superior characteristics, namely: a band larger than the $2 \mathrm{kHz}$ standard, actually upwards of $3 \mathrm{kHz}$; a $15 \mathrm{pT} \mathrm{rms} / \sqrt{ } \mathrm{Hz}$ noise and a lower-than-standard phase error.

The parameters of the data logger-acquisition module are controlled by a software programme assuring a sample rate of 5 seconds and displays the average values at every 60 seconds.

Special shelters were provided for the equipment and special work was carried out to place the electric sensors and lay out quite a length of cable connecting the various components of the observatory. The magnetic equipment is placed in a specially designed, vibration-proof, nonmagnetic, thermostatic tunnel. Similar conditions are not yet ensured at Vrâncioaia Observatory. 


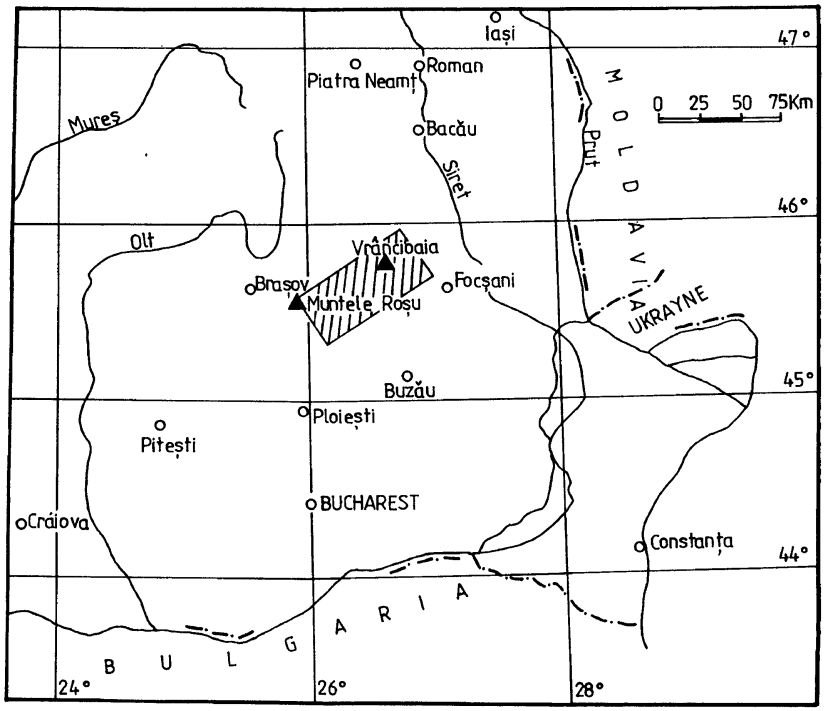

Fig. 1. Map locations of Muntele Roşu and Vrâncioaia electromagnetic observatories (full triangles); shaded rectangle $=$ the Vrancea epicentral zone.

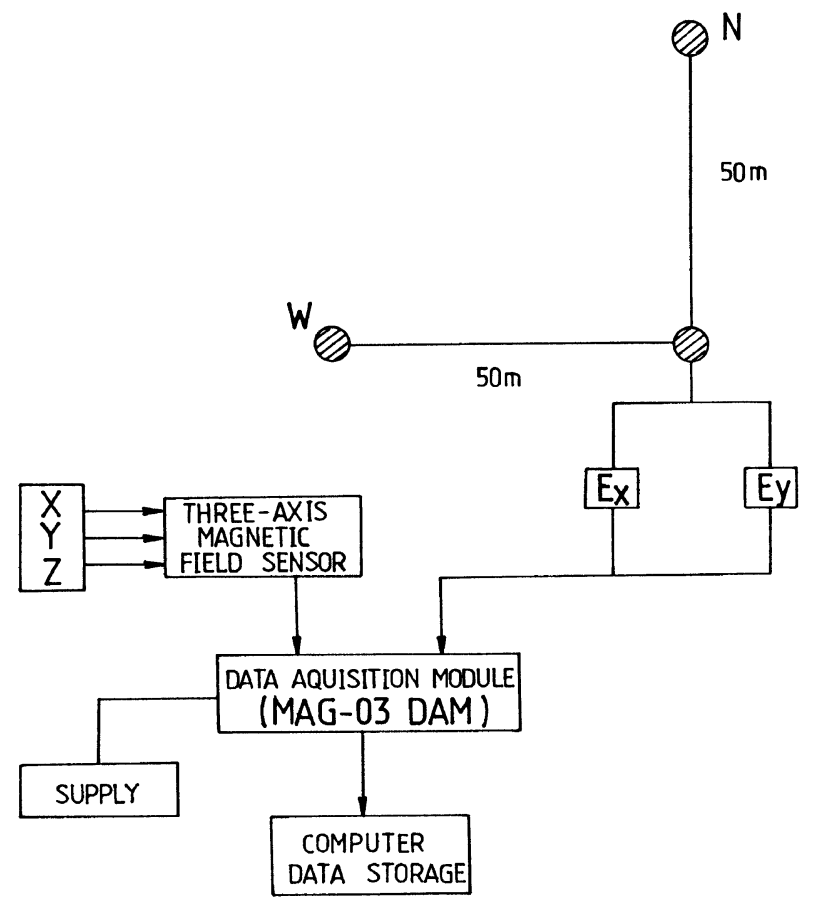

Fig. 2. General diagram of an electromagnetic observatory; shaded circles $=$ nonpolarizable electric sensors.

\section{Observation Data: Preliminary Results}

Data recording and preliminary processing yielded time variation diagrams of the magnetic and electric components; namely, three diagrams refer to the components of magnetic flux density, $B_{X}, B_{Y}$ and $B_{Z}$, and two others to the horizontal components $-E_{X}$ and $E_{Y}-$ of the electric field. The time (in days) is given on the abscissa and the values of the above components, in $\mu \mathrm{T}$ (for magnetic records) and in $\mathrm{mV} / \mathrm{km}$ (for electric records) are given on the ordinate (Figs. 3-18). $X$ is positive pointing North and $Y$ is positive pointing East. The time scale is not the same on all diagrams; however, the time can easily be measured as the beginning and end of every diagram are shown on the abscissa. Figures 3-18 display the diagrams of records made at Muntele Roşu Observatory. These are extremely accurate, highly reliable records, particularly the magnetic ones, thanks to the nearly ideal isolation of the observatory; the optimum location of the equipment in a specially designed, vibration-proof, nonmagnetic, thermostatic tunnel; and the high-level training of the personnel in charge of the devices.

The equipment was purchased in the fall of 1996 and the first stage of the experiment got started in December the same year. It had to stop shortly afterward, in January of 1997, because the computer was having trouble with the time recording and, most importantly, steps had to be taken to improve cable and equipment protection against atmospheric discharges and other phenomena. As a result, recording operations could not resume until December, 1997.

Consequently, the results referred to in this paper were obtained in the period December 24, 1996, to January 12, 1997 (Figs. 3(a) and 13(a)), and again in the period December, 1997, to September, 1998 (Figs. 3(b)-12 and 13(b)-18).

\subsection{Possible seismic-magnetic precursors}

The records of the three magnetic components, $B_{X}, B_{Y}$ and $B_{Z}$, are shown in Figs. 3-12 which also show the times when Vrancea earthquakes of magnitudes $M_{D} \geq 3.9$ occurred during the period of this study. Here $M_{D}$ is the magnitude that was determined by using earthquake duration as measured on the seismograms (Oncescu et al., 1998). The 3.9 magnitude was imposed as a threshold since significant disturbances could not be detected before the Vrancea earthquakes of $M_{D}$ less than 3.9.

Table 1 provides the parameters of all Vrancea earthquakes of magnitudes $M_{D} \geq 3.9$ occurring in the period under investigation. These data are reprinted after the Romanian Earthquake Catalogue (see Oncescu et al., 1998), compiled by the Seismological Department of the Romanian National Institute of Earth Physics. The Table shows the hour and date when earthquakes occurred, the geographical coordinates of their epicenters, $\varphi_{N}$ and $\lambda_{E}$, the depth, $h$, of their hypocenters, and the magnitude, $M_{D}$. The components of the magnetic flux density $(B)$, which manifest precursor perturbations, are also given in the Table for each earthquake. The approximate values of the precursor time, $t_{p B}$, are entered on one column, while another column includes assessments, which are of course of a subjective nature, of the quality, $q_{B}$, of the precursor perturbations (Figs. 3-12). The precursor time was measured from the onset of the magnetic anomaly to the moment the earthquake occurred. It is obviously impossible to demonstrate in this study whether or not there is any relation between precursor time and earthquake magnitude.

The data in Figs. 3-12 show that significant magnetic anomalies (perturbations) arose prior to earthquakes of magnitudes $M_{D} \geq 3.9$ during the period of the study, except for two earthquakes of March 6, $1998\left(M_{D}=4.0\right)$ in Fig. 5(a), and June 2, $1998\left(M_{D}=3.9\right)$ in Fig. 7(b). In very few cases, magnetic perturbations were also recorded immediately after the earthquakes (e.g., records in Fig. 5(a)). From Table 1, one finds that in 10 out of a total 19 earthquakes of $M_{D} \geq 3.9$, occurring in the investigated period, all of the 

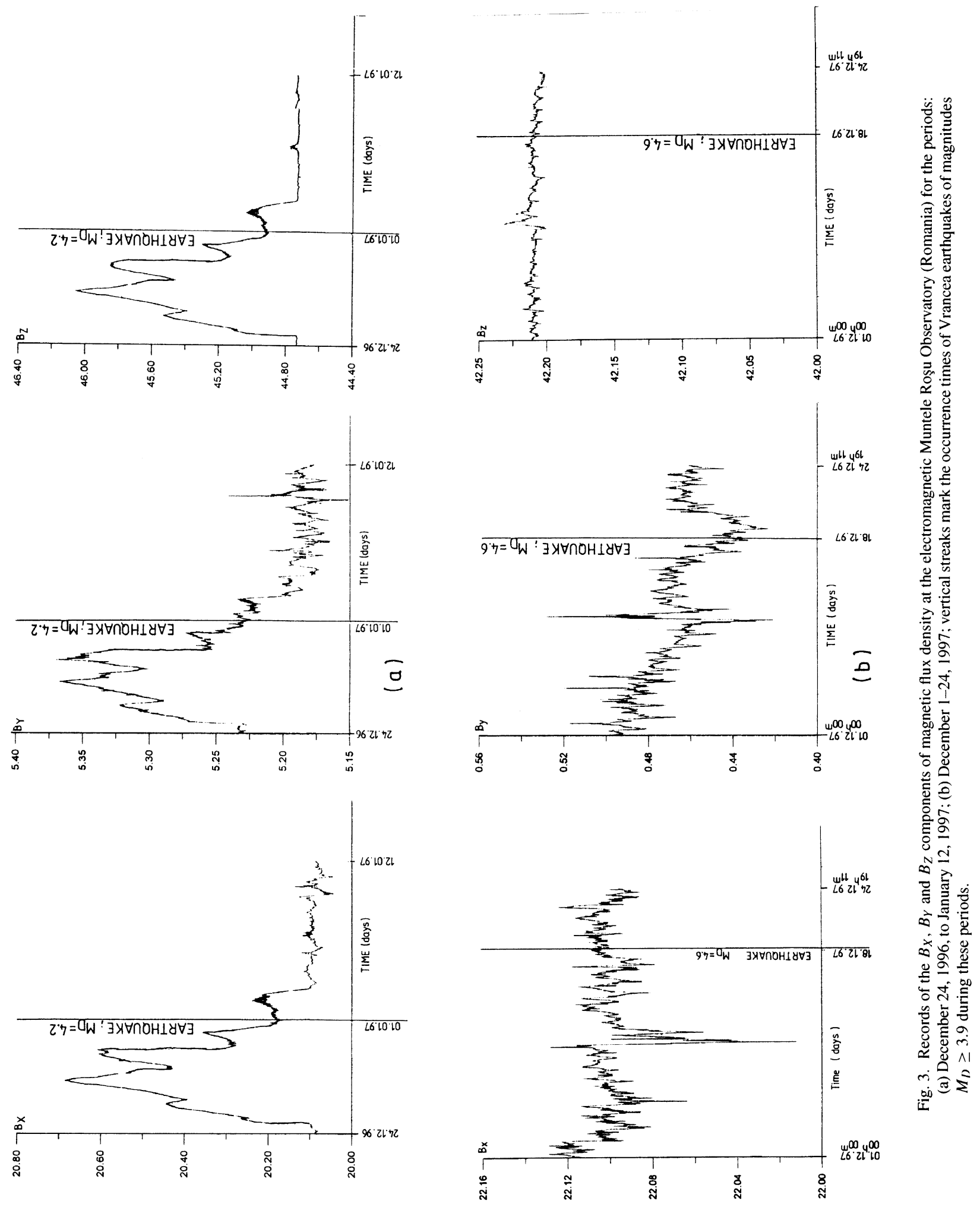

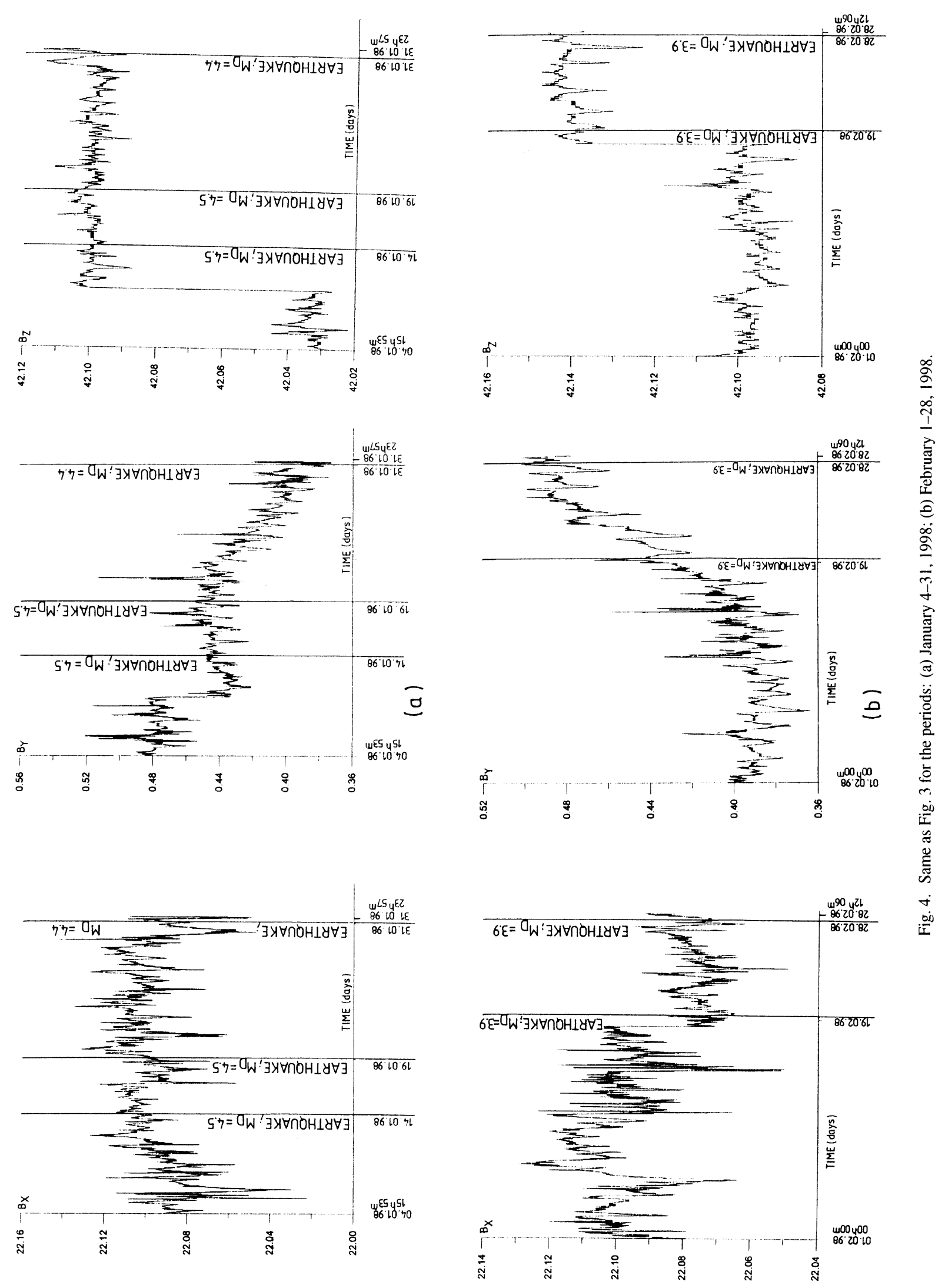

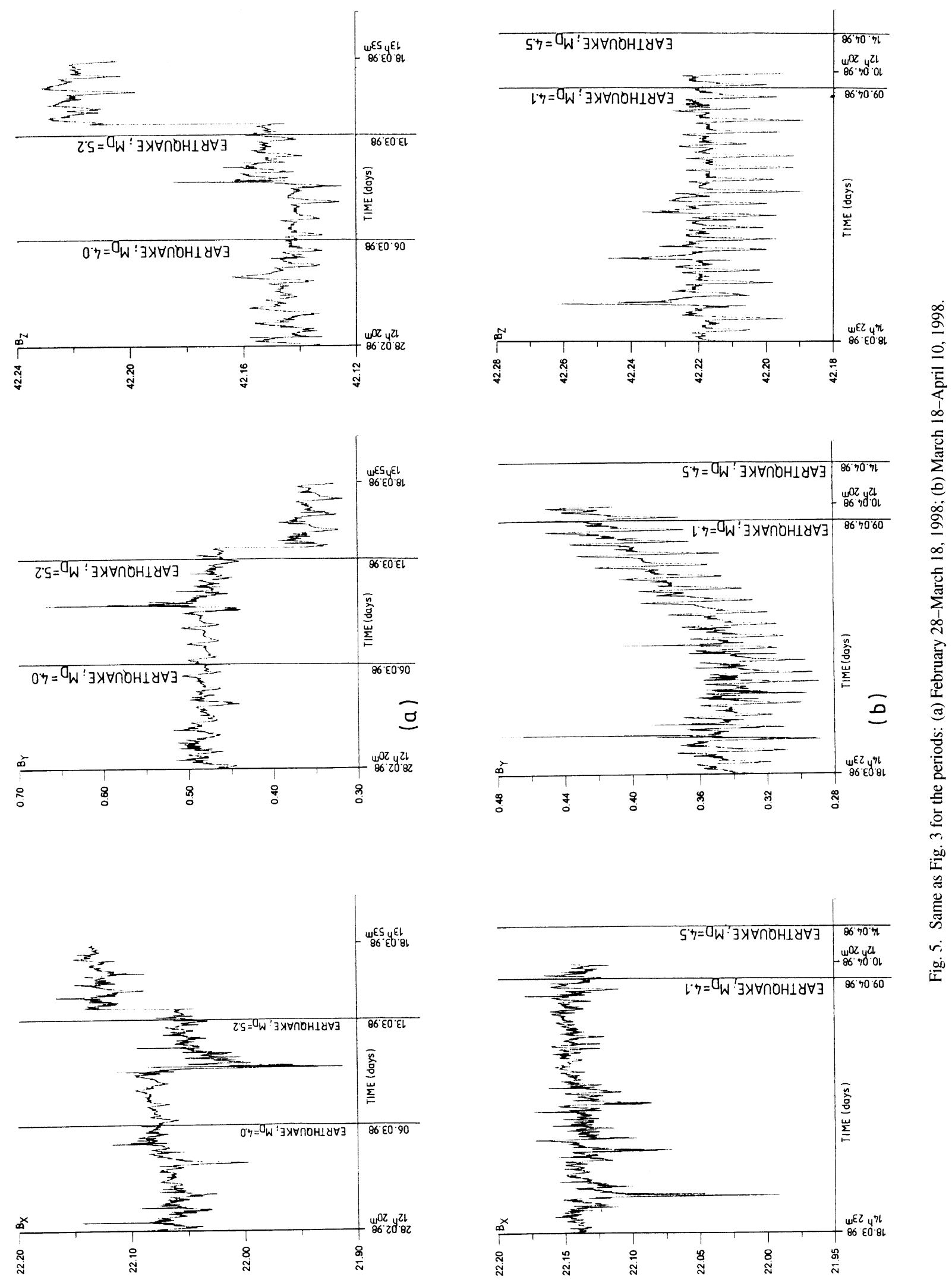

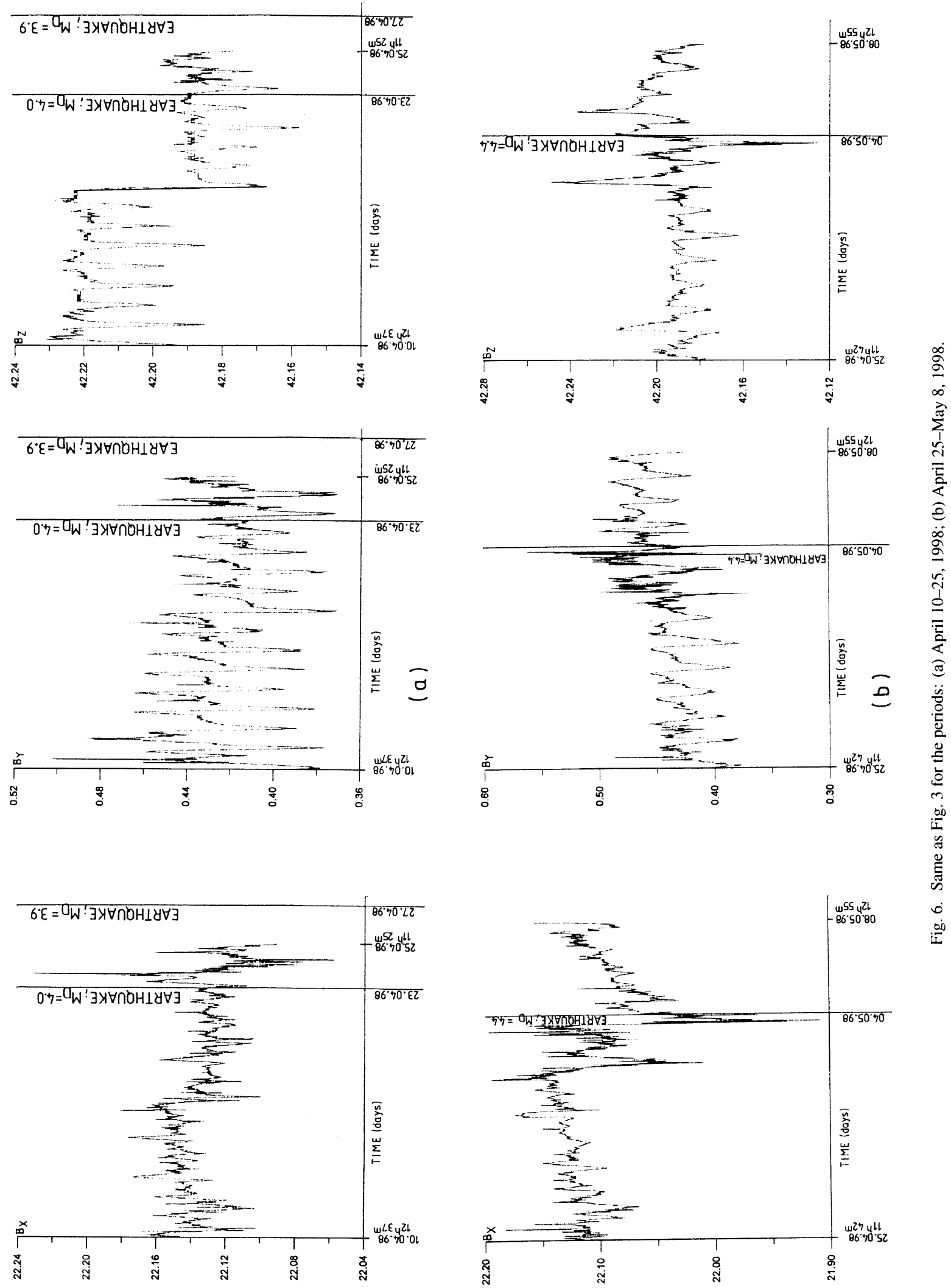

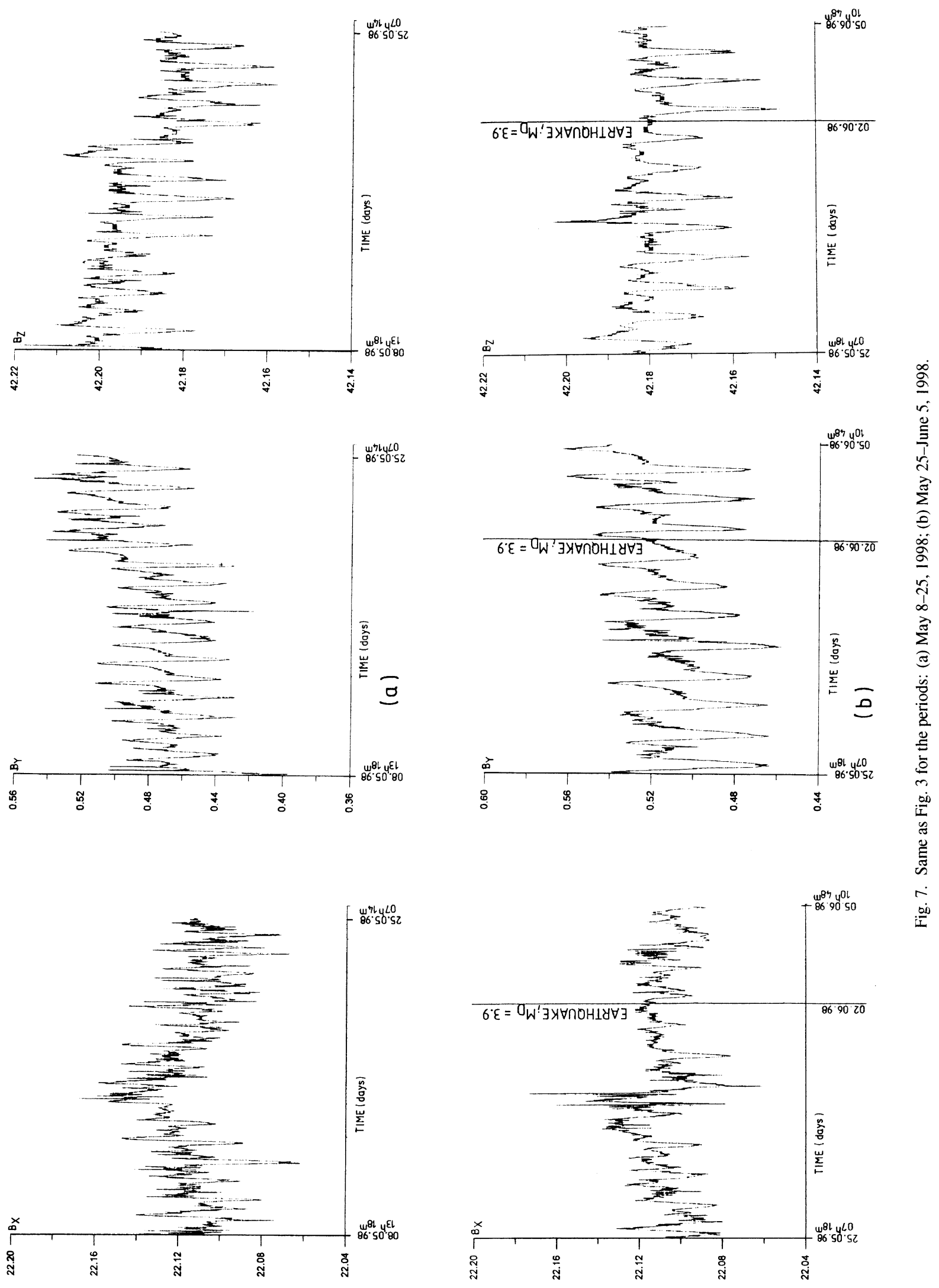

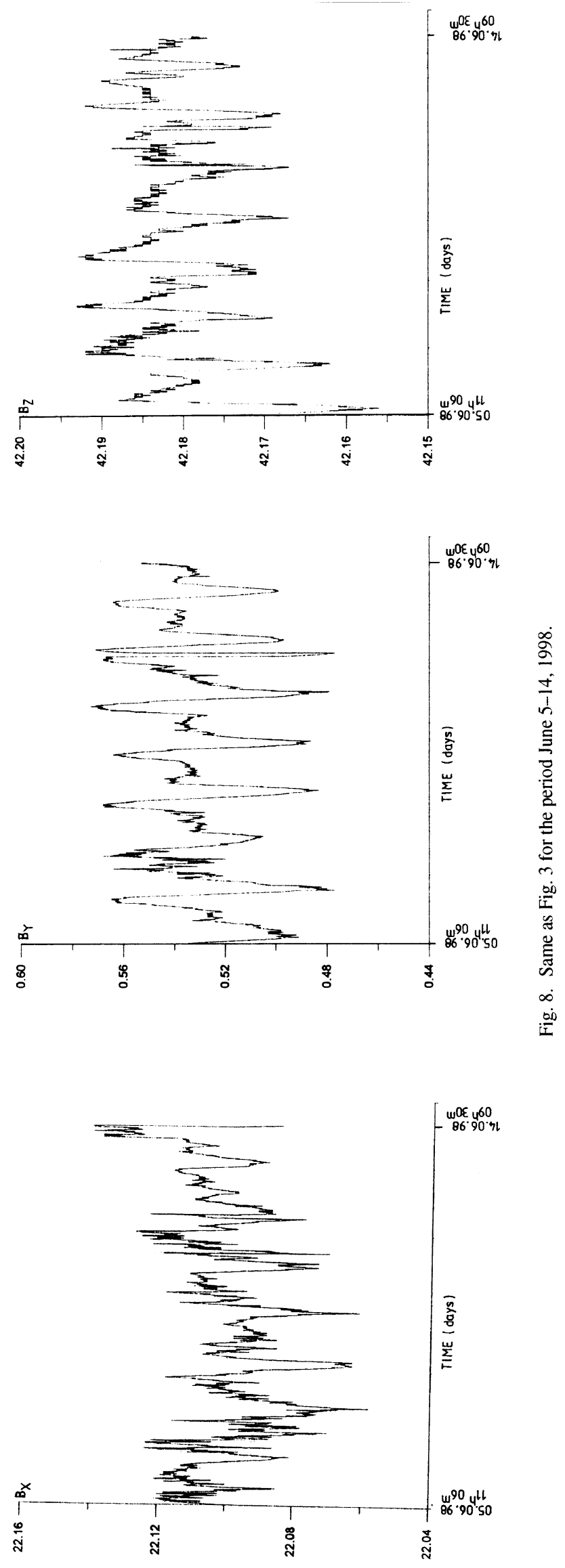

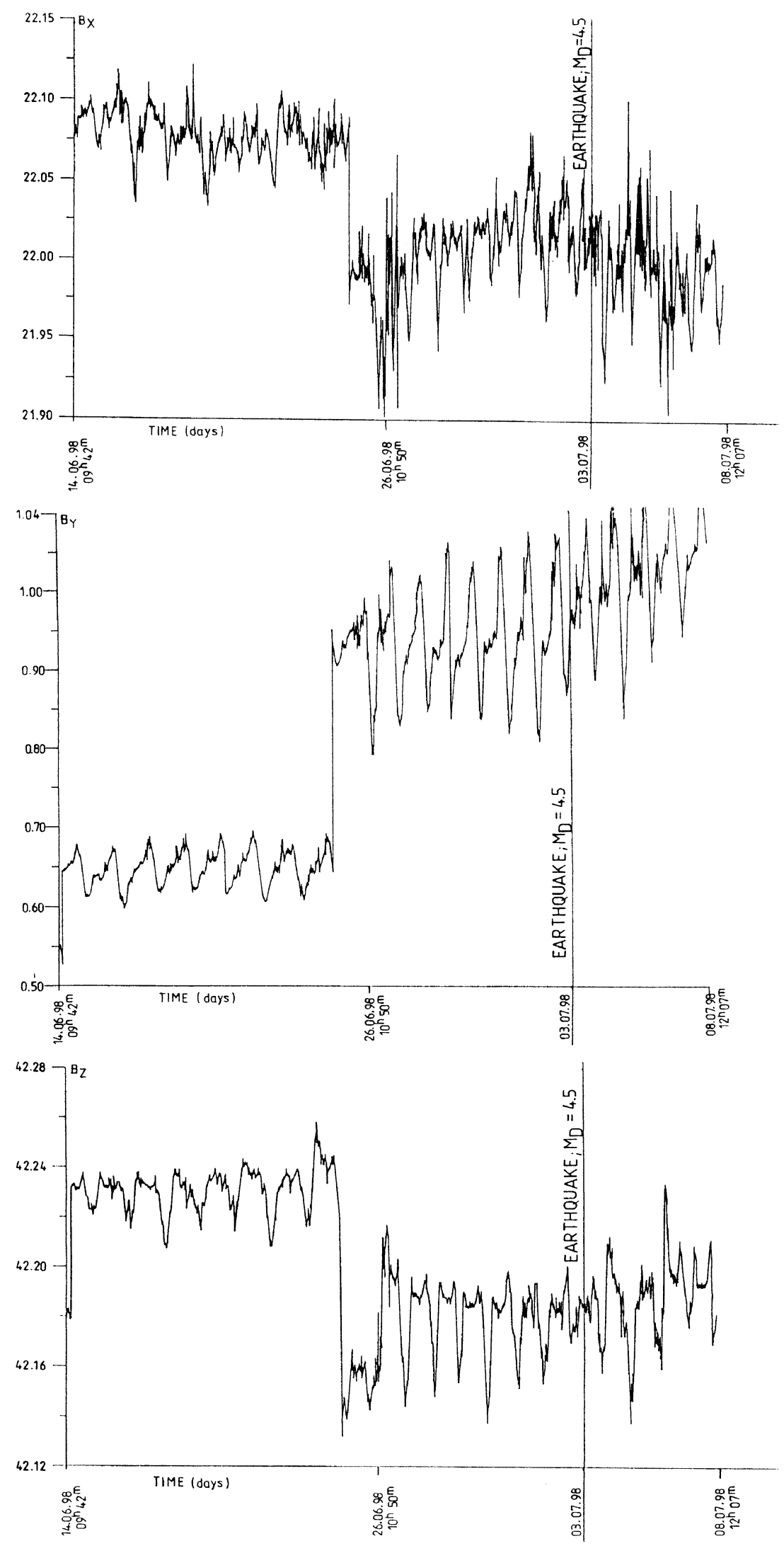

Fig. 9. Same as Fig. 3 for the period June 14-July 8, 1998. 

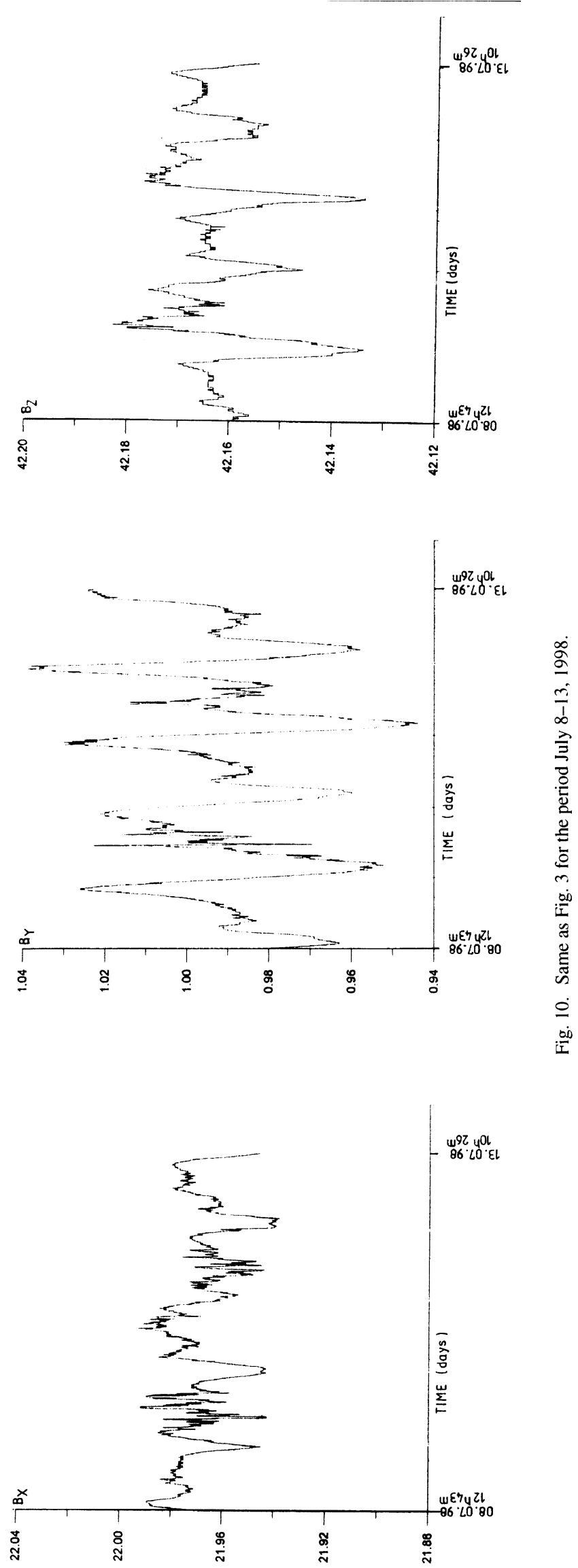

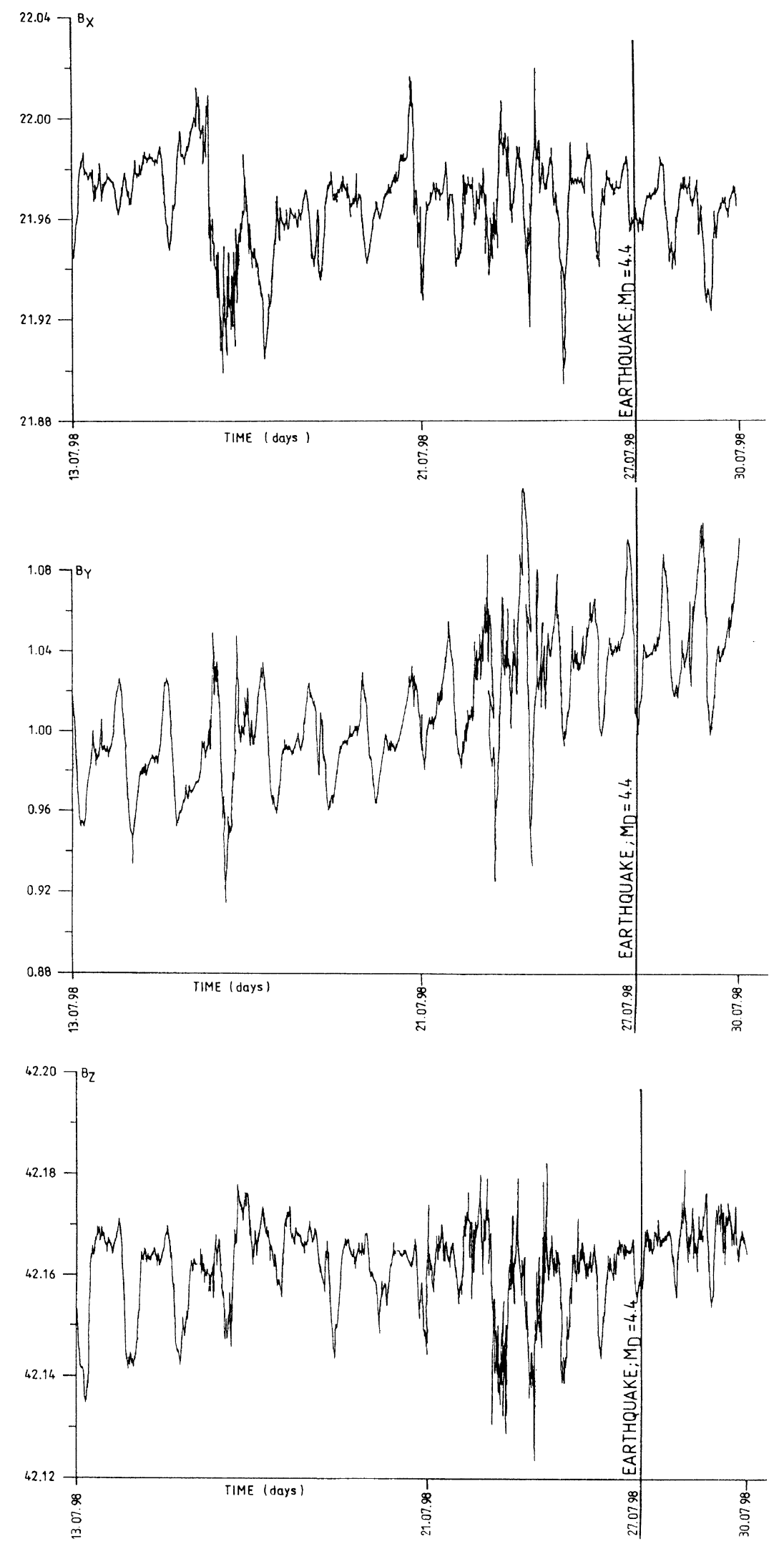

Fig. 11. Same as Fig. 3 for the period July 13-30, 1998. 

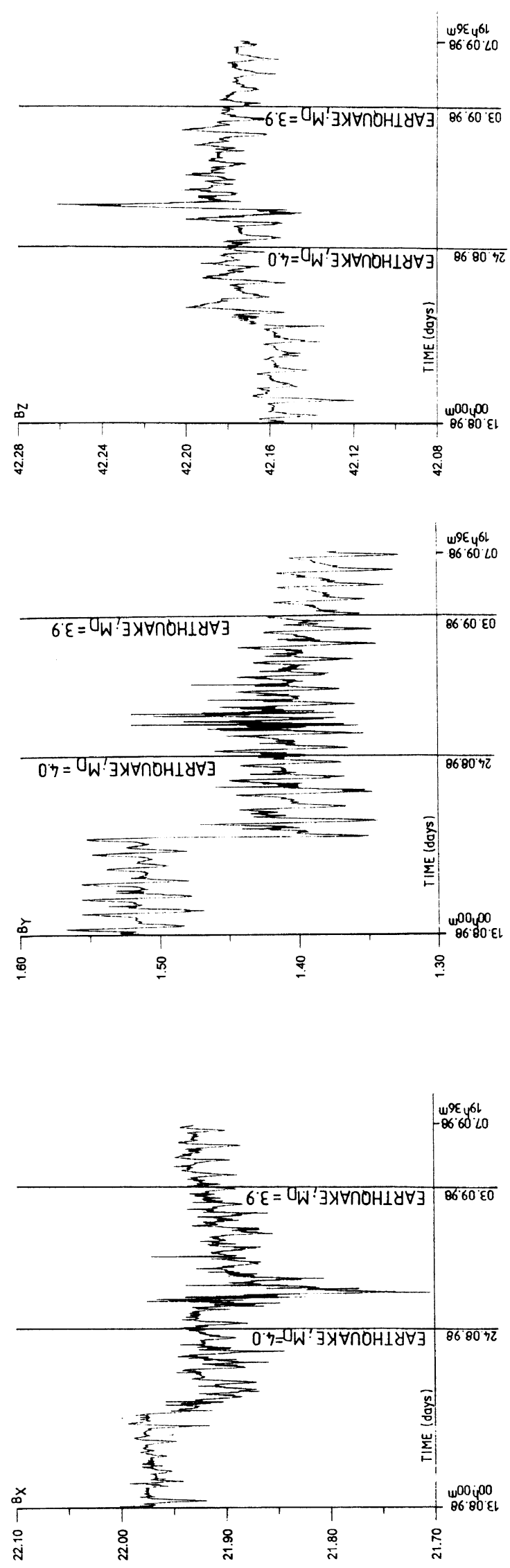

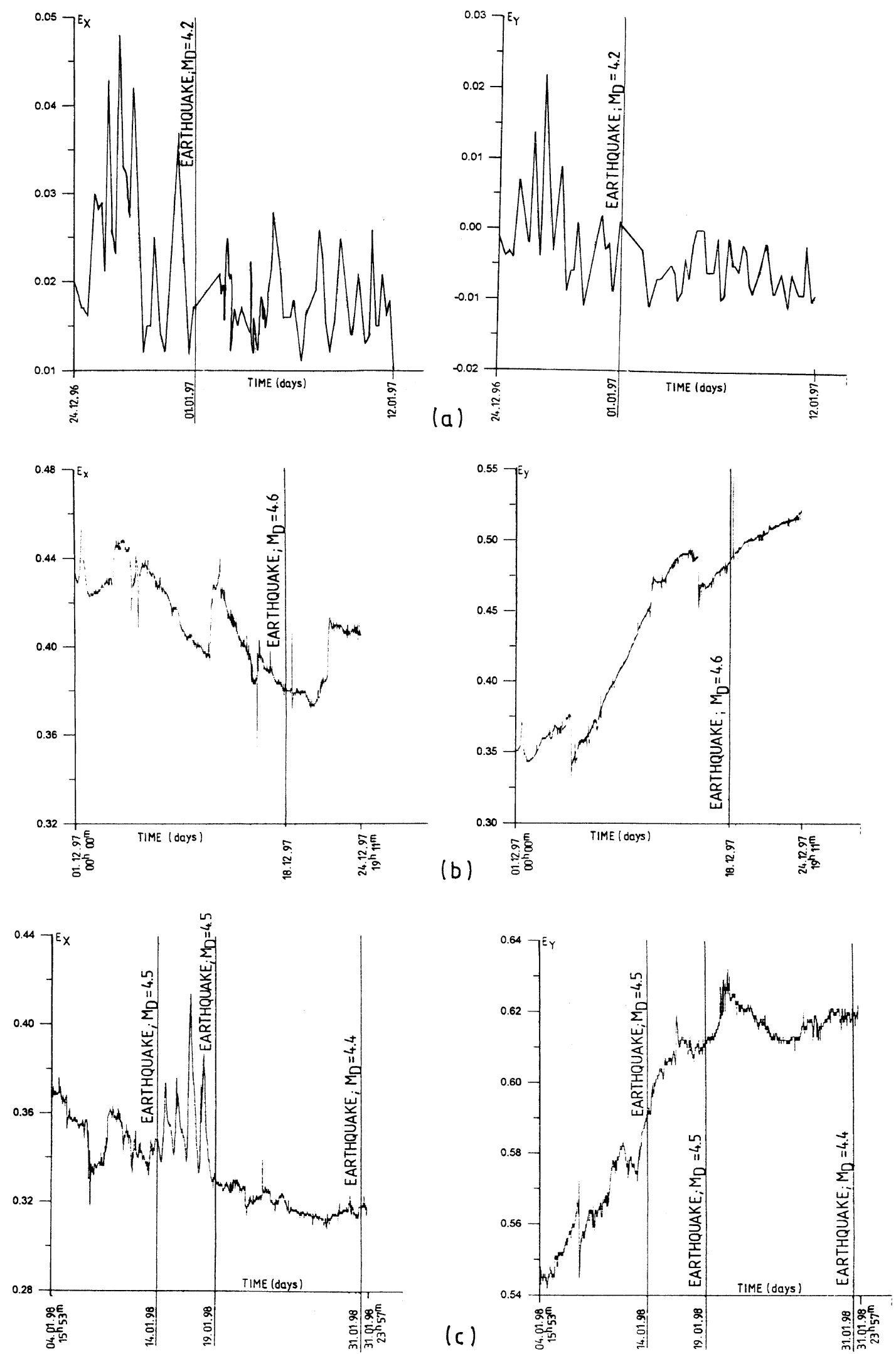

Fig. 13. Records of horizontal components, $E_{X}$ and $E_{Y}$, of the electric field at the electromagnetic Muntele Roşu Observatory (Romania) for the periods: (a) December 24, 1996, to January 12, 1997; (b) December 1-24, 1997; (c) January 4-31, 1998; vertical streaks mark the occurrence times of Vrancea earthquakes of magnitudes $M_{D} \geq 3.9$ during these periods. 

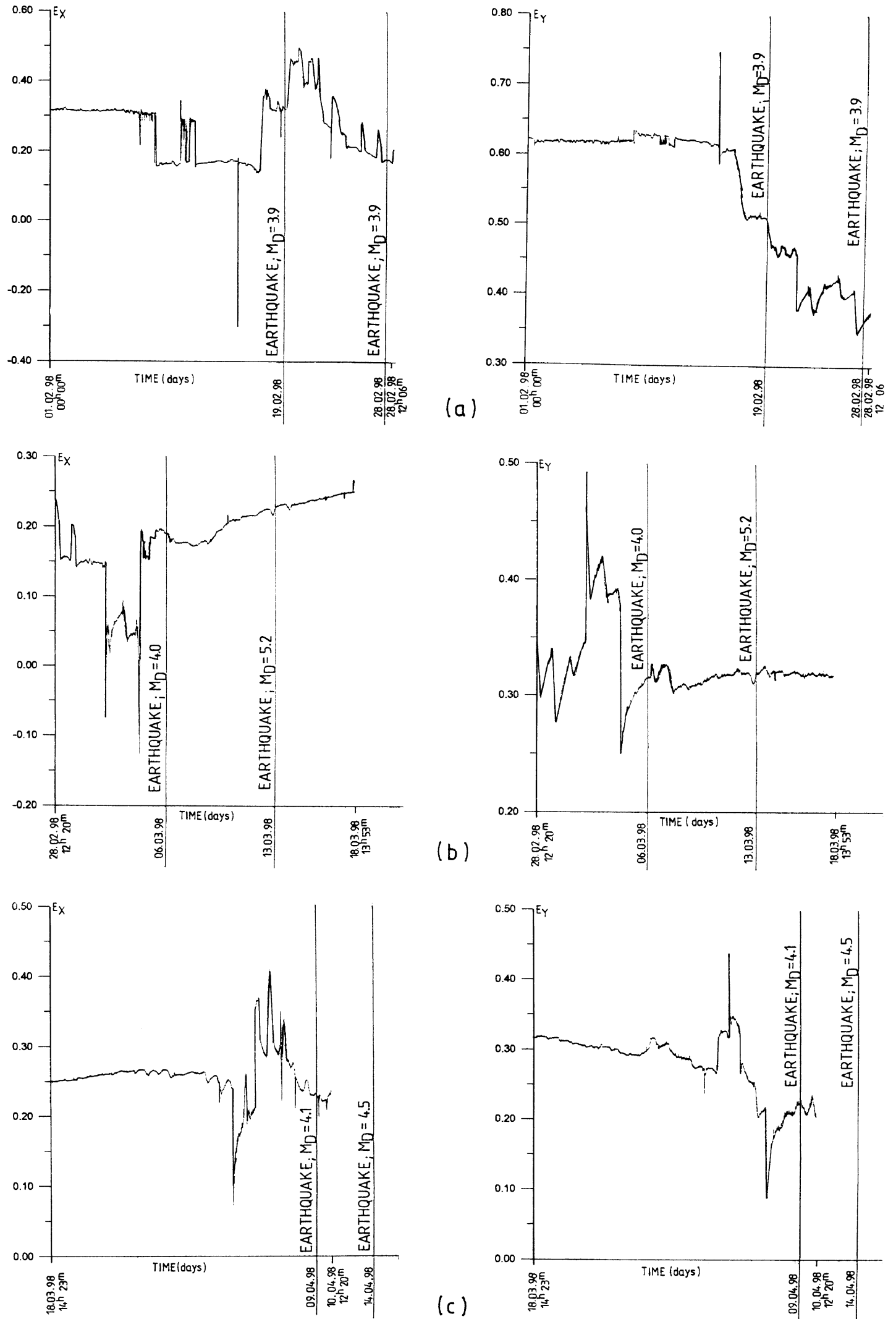

(b)

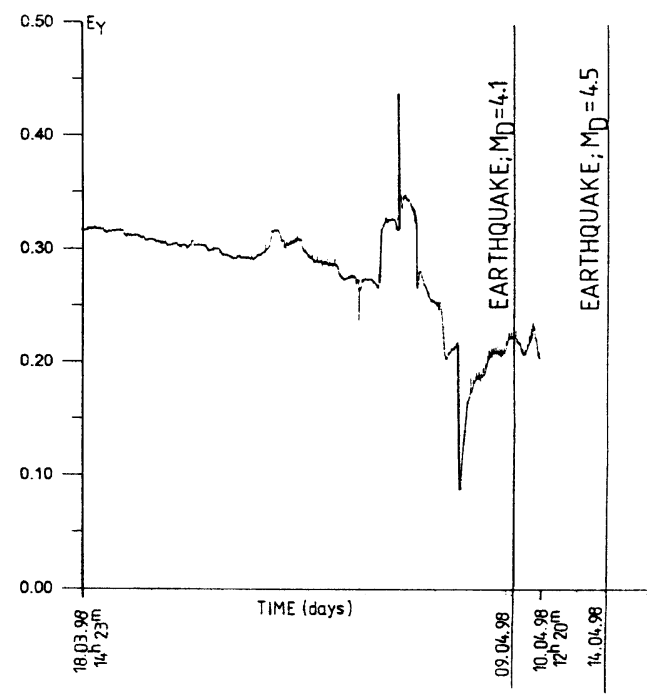

Fig. 14. Same as Fig. 13 for the periods: (a) February 1-28, 1998; (b) February 28-March 18, 1998; (c) March 18-April 10, 1998. 

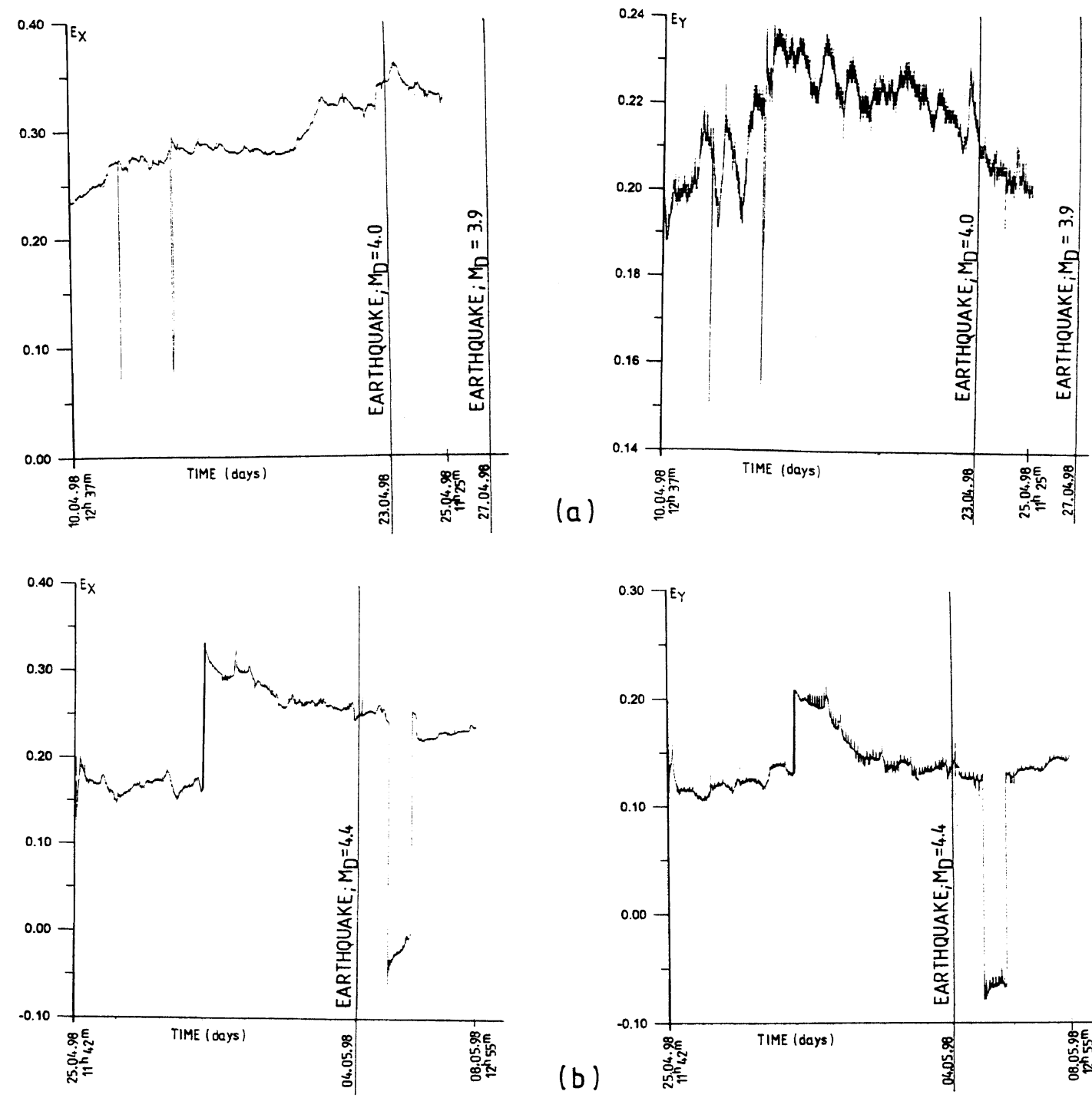

(b)
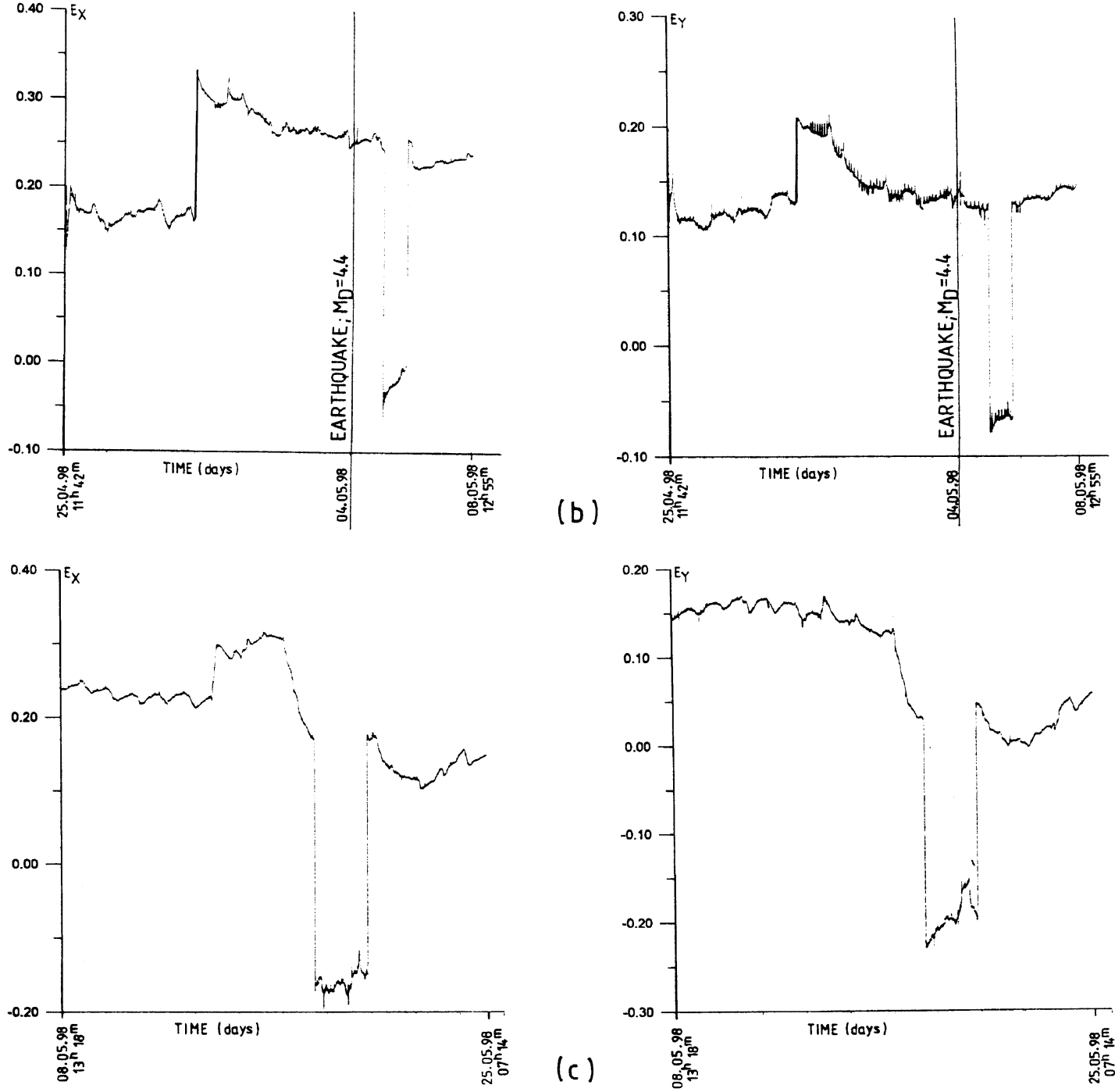

(c)

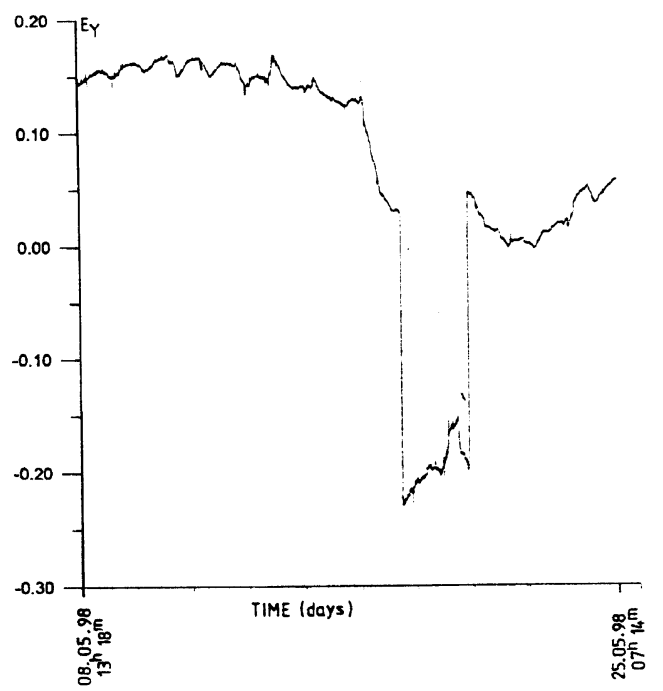

Fig. 15. Same as Fig. 13 for the periods: (a) April 10-25, 1998; (b) April 25-May 8, 1998; (c) May 8-25, 1998. 

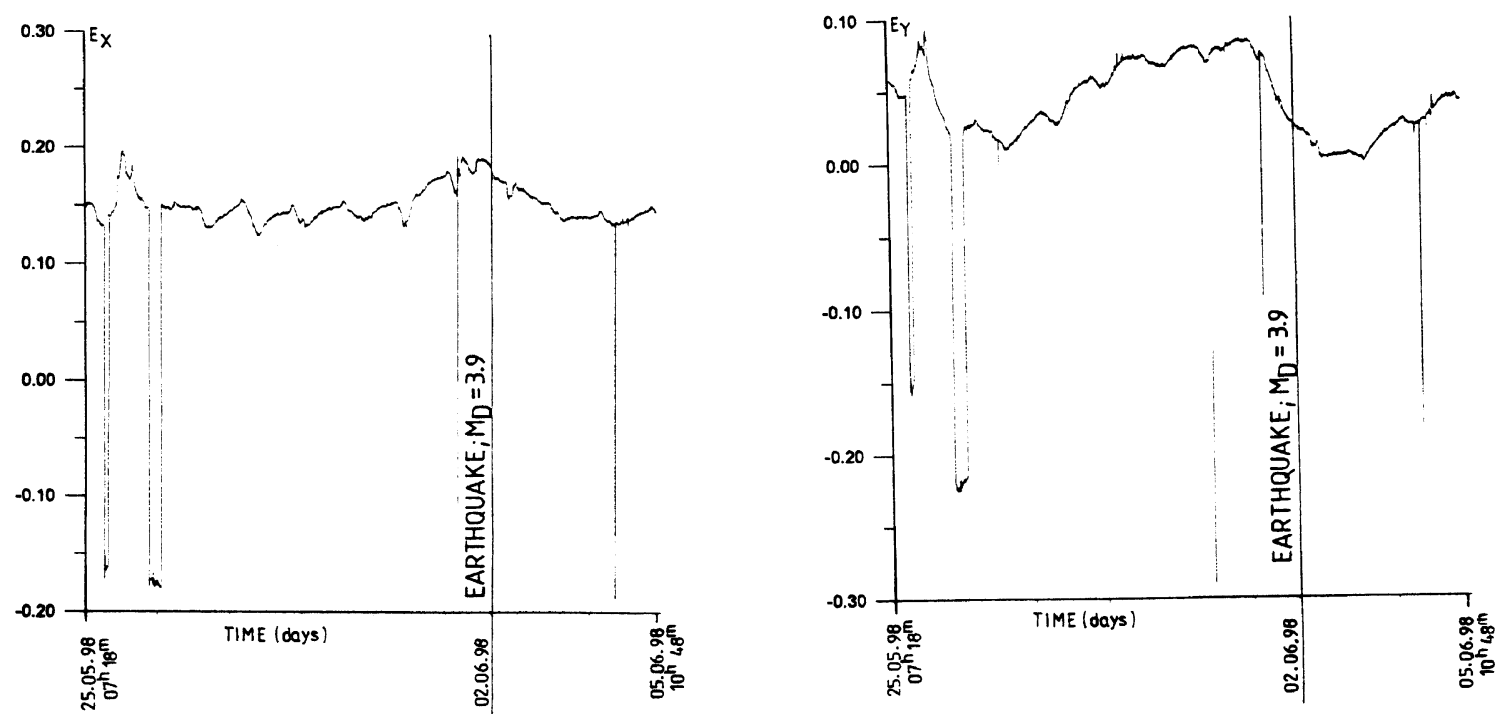

(a)
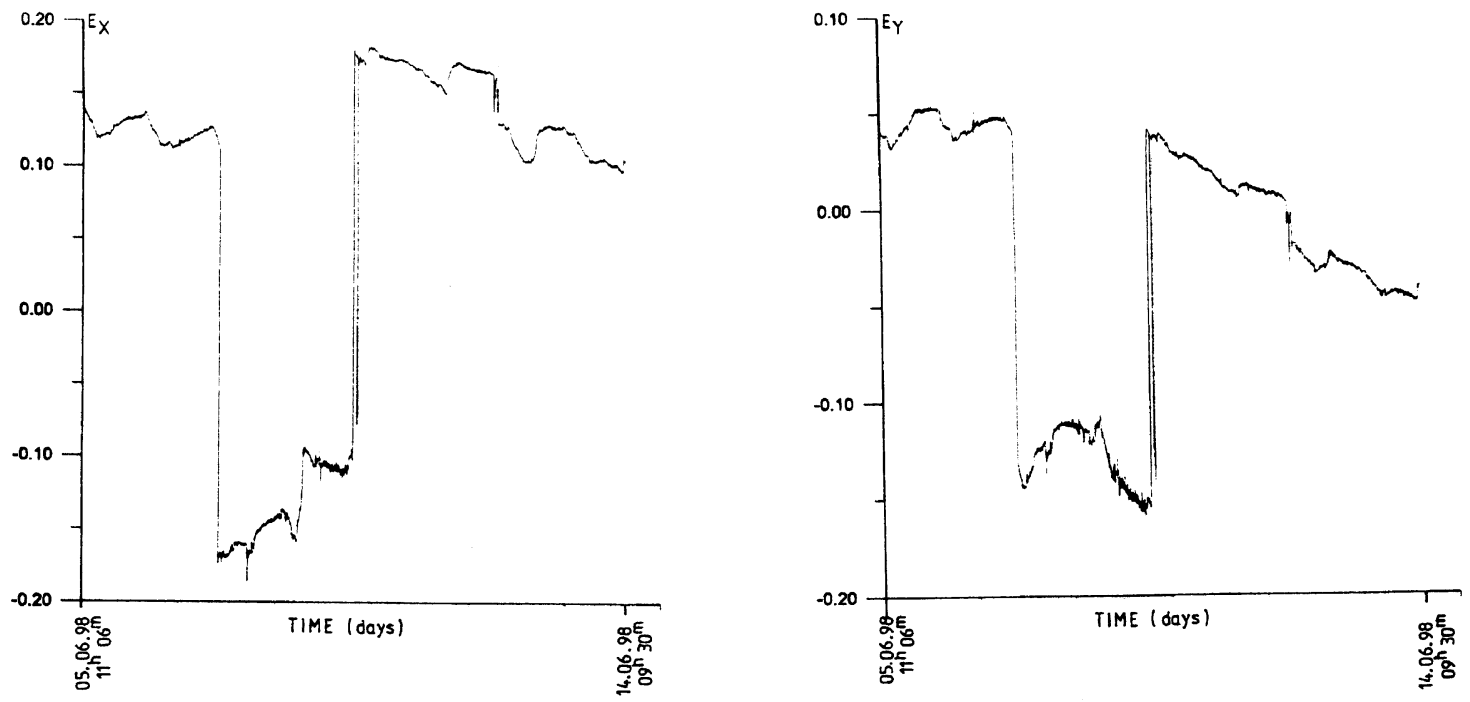

(b)

Fig. 16. Same as Fig. 13 for the periods: (a) May 25-June 5, 1998; (b) June 5-14, 1998.

three magnetic components were disturbed by anomalies; in seven other earthquakes, only two components were affected, while in two earthquakes (of threshold or close-to-threshold magnitude, $M_{D}=3.9$ ), anomalies were found in just one component, and even those were unconvincing.

It is important to note that precursor anomalies very evidently appeared even before the one crustal earthquake of $M_{D}=3.9$ occurring within the period of the study, namely the seism of September 3, 1998 (see Table 1).

The anomalies occurred in the form of sudden or relatively slow amplitude variations of the magnetic signal, occasionally accompanied by changes in the frequency spectrum, namely an increase in high frequencies. The anomalous changes in the magnetic records can be classified roughly into three types. The first is step-type change as in e.g., Fig. 9. The second is anomalous change with high frequency as in e.g., Fig. 11. The third is anomalous change with low frequency and very large amplitude as in Fig. 3(a). It is probably that these anomalous changes were not due in all cases to physical-mechanical events arising in the areas where the earthquakes, marked in the diagrams, were just being prepared, but due either to problems of the instruments or to some geomagnetic storms. Still, the used magnetic instruments are of very good quality and they were set up very well. It is also important to note that, apart from the common diurnal variation of the geomagnetic field, no significant magnetic perturbations were recorded in the intervals when no earthquake of $M_{D} \geq 3.9$ occurred in the Vrancea area (see Figs. 7(a), 8, 10, etc). Consequently, it may be considered that Vrancea earthquakes are preceded by magnetic anomalies (perturbations) which may be regarded as their short-term precursors. 

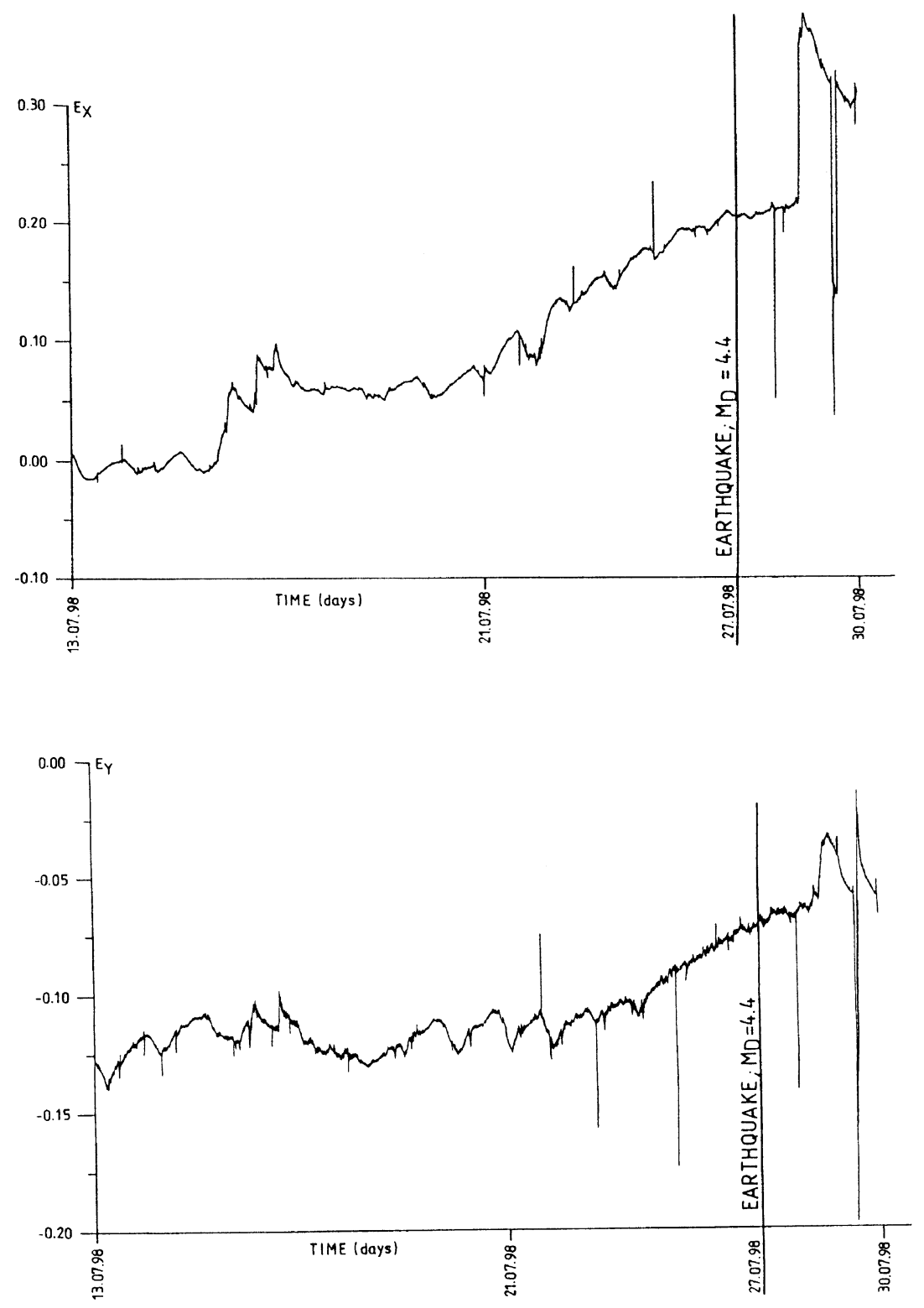

Fig. 17. Same as Fig. 13 for the period July 13-30, 1998.
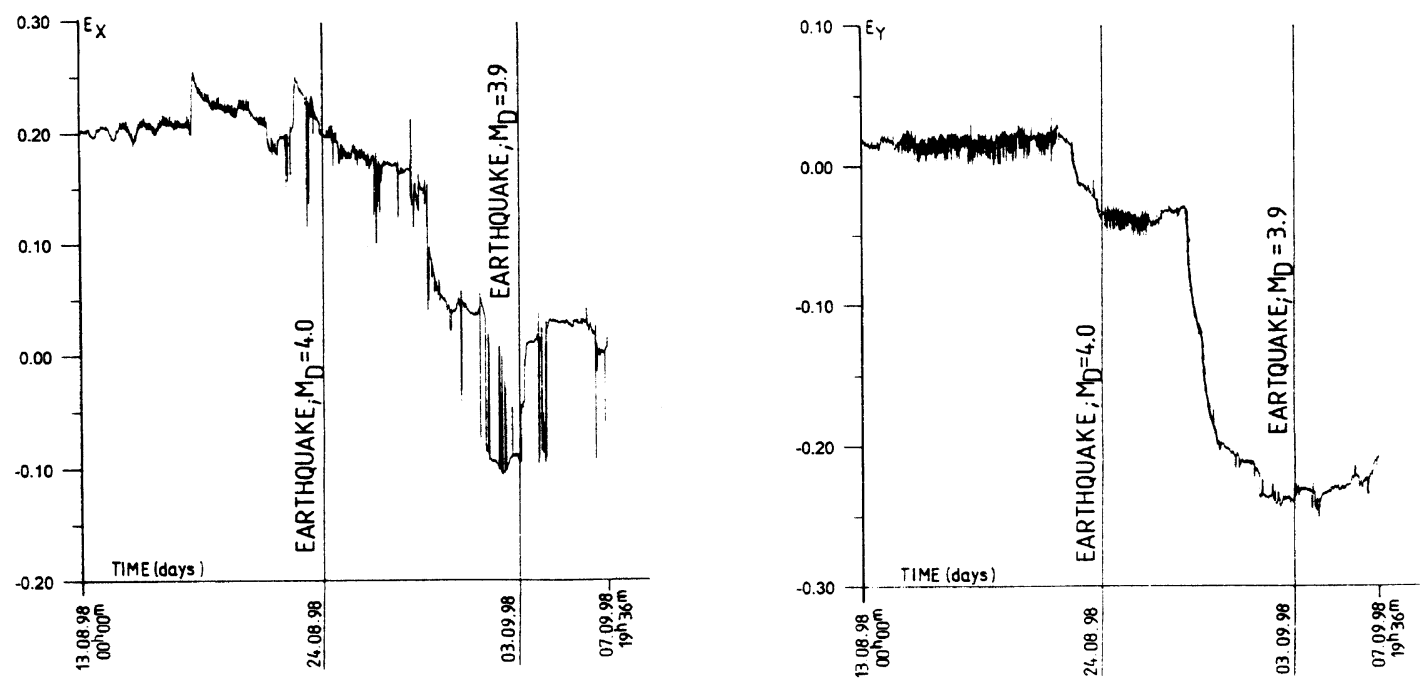

Fig. 18. Same as Fig. 13 for the period August 13-September 7, 1998. 
Table 1. Seismological parameters and electromagnetic precursory data of all Vrancea earthquakes of magnitudes $M_{D} \geq 3.9$ occurred in the period under investigation.

\begin{tabular}{|c|c|c|c|c|c|c|c|c|c|c|c|}
\hline Nr. & Date & $\begin{array}{l}\text { Time } \\
\text { (GMT) }\end{array}$ & $\varphi_{N}^{0}$ & $\lambda_{E}^{0}$ & $\mathrm{~h}(\mathrm{~km})$ & $M_{D}$ & $B$ & $\begin{array}{c}t_{p B} \\
\text { (days) }\end{array}$ & $q_{B}$ & $E$ & $q_{E}$ \\
\hline 1 & 01.01 .1997 & 01:44 & 45.7 & 26.6 & 141 & 4.2 & $B_{X}, B_{Y}, B_{Z}$ & 7 & v.g. & $E_{X}, E_{Y}$ & v.g. \\
\hline 2 & 18.12.1997 & $23: 21$ & 45.5 & 26.3 & 134 & 4.6 & $B_{X}, B_{Y}, B_{Z}$ & $7-8$ & $\mathrm{~g}$ & $E_{X}, E_{Y}$ & v.g. \\
\hline 3 & 14.01 .1998 & 05:02 & 45.7 & 26.6 & 145 & 4.5 & $-B_{Y}, B_{Z}$ & $4-5$ & v.g. & $-E_{Y}$ & $\mathrm{~s}$ \\
\hline 4 & 19.01 .1998 & $00: 54$ & 45.6 & 26.7 & 105 & 4.5 & $-B_{Y}, B_{Z}$ & 9 & v.g. & $E_{X}, E_{Y}$ & $\mathrm{~g}$ \\
\hline 5 & 31.01 .1998 & $21: 14$ & 45.5 & 26.3 & 136 & 4.4 & $-B_{Y}, B_{Z}$ & 21 & v.g. & $E_{X}, E_{Y}$ & $\mathrm{~s}$ \\
\hline 6 & 19.02 .1998 & $14: 35$ & 45.7 & 26.7 & 132 & 3.9 & $B_{X}, B_{Y}, B_{Z}$ & 1 & v.g. & $E_{X}, E_{Y}$ & v.g. \\
\hline 7 & 28.02 .1998 & $08: 37$ & 45.4 & 26.2 & 139 & 3.9 & $B_{X}, B_{Y}, B_{Z}$ & $9-10$ & v.g. & $E_{X}, E_{Y}$ & v.g. \\
\hline 8 & 06.03 .1998 & $20: 28$ & 45.6 & 26.4 & 151 & 4.0 & $B_{X}--$ & 3 & uns. & $E_{X}, E_{Y}$ & v.g. \\
\hline 9 & 13.03 .1998 & $13: 14$ & 45.6 & 26.4 & 155 & 5.2 & $B_{X}, B_{Y}, B_{Z}$ & $3-4$ & $\mathrm{~g}$ & $E_{X}, E_{Y}$ & v.g. \\
\hline 10 & 09.04 .1998 & $10: 25$ & 45.4 & 26.4 & 133 & 4.1 & $B_{X}, B_{Y}-$ & 7 & $\mathrm{~s}$ & $E_{X}, E_{Y}$ & v.g. \\
\hline 11 & 14.04 .1998 & 01:03 & 45.7 & 26.6 & 147 & 4.5 & $B_{X}, B_{Y}-$ & 12 & $\mathrm{~s}$ & $E_{X}, E_{Y}$ & g \\
\hline 12 & 23.04 .1998 & $06: 37$ & 45.8 & 26.7 & 90 & 4.0 & $B_{X}-B_{Z}$ & 5 & $\mathrm{~g}$ & $E_{X}, E_{Y}$ & s \\
\hline 13 & 27.04 .1998 & 09:31 & 45.7 & 26.5 & 155 & 3.9 & $B_{X}-B_{Z}$ & 9 & $\mathrm{~s}$ & $E_{X}, E_{Y}$ & $\mathrm{~s}$ \\
\hline 14 & 04.05 .1998 & $16: 10$ & 45.7 & 26.5 & 139 & 4.4 & $B_{X}, B_{Y}, B_{Z}$ & 2 & v.g. & $E_{X}, E_{Y}$ & g \\
\hline 15 & 02.06 .1998 & 04:49 & 45.6 & 26.5 & 110 & 3.9 & $B_{X}--$ & $3-4$ & $\mathrm{~s}$ & $E_{X}, E_{Y}$ & $\mathrm{~s}$ \\
\hline 16 & 03.07 .1998 & $06: 14$ & 45.7 & 26.8 & 133 & 4.5 & $B_{X}, B_{Y}, B_{Z}$ & 8 & v.g. & -- & uns. \\
\hline 17 & 27.07.1998 & $15: 02$ & 45.7 & 26.5 & 132 & 4.4 & $B_{X}, B_{Y}, B_{Z}$ & 4 & $\mathrm{~s}$ & $E_{X}, E_{Y}$ & g \\
\hline 18 & 24.08 .1998 & $23: 27$ & 45.6 & 26.5 & 152 & 4.0 & $B_{X}, B_{Y}, B_{Z}$ & 4 & v.g. & $E_{X}, E_{Y}$ & g \\
\hline 19 & 03.09 .1998 & $13: 42$ & 46.8 & 26.4 & 25 & 3.9 & $B_{X}, B_{Y}, B_{Z}$ & $5-6$ & v.g. & $E_{X}, E_{Y}$ & v.g. \\
\hline
\end{tabular}

v.g. $=$ very good; $\mathrm{g}=$ good; $\mathrm{s}=$ satisfactory; uns. = unsatisfactory.

\subsection{Possible seismic-electric precursors}

Figures 13-18 show records of the electric components, $E_{X}$ and $E_{Y}$, during the time interval under consideration, except for the earlier mentioned gaps. The last but one column in Table 1 indicates the components on which electric anomalies (perturbations) occur in relation to the earthquakes under investigation. The last column contains assessments, which of course are again of a subjective nature, regarding the quality, $q_{E}$, of the electric anomalies (perturbations) that are found to accompany earthquakes of magnitudes $M_{D} \geq 3.9$.

The electric anomalies, which are assumed to act as precursors, appear in the form of relatively sudden (see, for example, Figs. 13(a); 14(a), (b), (c) and 15(b)) or slow (see, for example, Figs. 13(b), (c) and 15(a)) variations in the signal amplitude, occasionally accompanied by frequency spectrum changes. The anomalies sometimes occur as a combination of the two types of variations. The records also show some very sudden, short variations (see, for example Figs. 15(a), (b), (c), and 16(a), (b)), which we believe are caused by factors other than the seismic one. We have left them out of the category of seismic-electric signals, neglecting them as noise.

A careful examination of the data in Figs. 13-18 reveals that the electric anomalies appearing in Figs. 13-15(b); 17 and 18 can be regarded as precursors of the Vrancea earthquakes. On the other hand, data in Figs. 15(c)-16(b) do seem to cast a doubt on this assumption. Thus, Fig. 15(c) does not indicate any earthquake of $M_{D} \geq 3.9$, and yet a slow variation in electric signal amplitude is found, overlapped by a sharp, sudden, short-time variation, which could be caused by different other factors, such as climate. The slow variation illustrated in Fig. 15(c) is either the result of a signal alteration by the climatic factor or a precursor of the four earthquakes of $M_{D}=3.0-3.3$, occurring on May 24 and 25, 1998 (see Oncescu et al., 1998). Either way, data interpretation becomes difficult. In the first alternative, the signal/noise ratio is too low (with the noise arising from other than seismic factors). If the second alternative is true, it follows that even earthquakes of $M_{D}<3.9$ can have a visible influence on electric signals. This would make it all but impossible to correlate electric and seismic data since earthquakes of $M_{D}<3.9$ are obviously much more frequent than those above this threshold. This would leave the door open for any interpretation, so we would have more than one solution to the problem. The remarks concerning data in Fig. 15(c) also apply to those in Fig. 16(b).

The very small amplitude of the electric anomaly in Fig. 16(a) could be accounted for by noting that it precedes 
an earthquake of $M_{D}=3.9$, equal to the lower limit of the magnitude range $\left(M_{D} \geq 3.9\right)$ for which seismic electromagnetic precursors are likely to occur in the case of Vrancea earthquakes.

The above analysis indicates that electric signals are less reliable than the magnetic ones in terms of their relation with the physical and mechanical phenomena occurring in the underground in advance of the Vrancea earthquakes. We believe this lower reliability can be blamed on the electric sensors: no matter how well made and placed, they still remain sensitive to other, especially climatic, factors. Since the records are of high quality for the most part (see Figs. 1315(b); 17 and 18), we think the records of the two electric components, $E_{X}$ and $E_{Y}$, are also useful. Along with the more reliable magnetic records and those of other precursors, they can lead to an integrated interpretation that would resolve the problem of seismic prediction much more effectively than would be possible by using records of a sole precursor.

\section{Conclusions}

The results reported in this paper lead to several main conclusions, which are summarized below:

- The significant magnetic anomalies (perturbations) preceding the occurrence of Vrancea earthquakes of magnitudes $M_{D} \geq 3.9$ pave the way to a short-term prediction of moderate and especially major seismic events in the investigated region.

- The correlation between Vrancea earthquakes and the anomalies affecting the horizontal components of the electric field is less reliable due to an occasionally high influence of other factors, especially climatic ones. Nevertheless, a majority of the data (Figs. 13-15(b); 17 and 18) argue for proceeding with the recording of these components.

- In the case of major Vrancea earthquakes $(M>6.5)$, the electromagnetic signals are likely to be more distinct than for lower magnitudes, and the precursor time would probably be longer than indicated in Table 1 .

- To improve prediction reliability, it is obviously imperative that several other potential precursors be monitored in addition to the electromagnetic ones.
- A systematic, rigorous real-time processing of the data is required to go beyond the results given in this paper where the existence of precursors is only a posteriori found. To this end, electromagnetic recording needs to go on at Muntele Roşu Observatory, and operating conditions of the electromagnetic equipment at Vrâncioaia Observatory need to be improved.

Acknowledgments. The authors are most indebted to Dr. Dumitru Stanica of the Romanian Geological Institute for his assistance with mounting of the electromagnetic equipment at Muntele Roşu and Vrâncioaia observatories, and his relevant suggestions while this work was in process. The authors are also greatly indebted to the reviewers whose comments and suggestions have substantially improved the paper.

\section{References}

Enescu, B. D., C. Ionescu, and D. Enescu, Establishment of two electromagnetic observatories in Vrancea (Romania) seismic area, Romanian Journal of Physics, 1999 (in press).

Ernst, T., J. Jankowski, C. Rozluski, and R. Teisseyre, Analysis of the electromagnetic field recorded in the Friuli seismic zone, northeast Italy, Tectonophysics, 224, 141-148, 1993.

Fraser-Smith, A. C., A. Bernardi, P. R. McGill, M. E. Ladd, R. A. Helliwell, and O. G. Villard, Jr., Low frequency magnetic field measurements near the epicenter of the $M_{S} 7.1$ Loma Prieta earthquake, Geophys. Res. Lett., 17, 1465-1468, 1990.

Gokhberg, M. B., V. A. Morgunov, T. Yoshino, and I. Tomizawa, Experimental measurement of electromagnetic emissions possibly related to earthquakes in Japan, J. Geophys. Res., 87, 7824-7828, 1982.

Honkura, Y., E. R. Niblett, and R. D. Kurtz, Changes in magnetic and telluric field in a seismically active region of Eastern Canada: preliminary results of earthquake prediction studies, Tectonophysics, 34, 219-230, 1976.

Johnston, M. J. S., Review of electric and magnetic fields accompanying seismic and volcanic activity, Surv. Geophys., 18, 441-475, 1997.

Oncescu, M. C., V. I. Marza, M. Rizescu, and M. Popa, The Romanian Earthquake Catalogue, 984-1996, Natural Hazards, 1998 (in press).

Park, S. K., M. J. S. Johnston, T. R. Madden, F. D. Morgan, and H. F. Morrison, Electromagnetic precursors to earthquakes in the ULF band: a review of observations and mechanisms, Rev. Geophys., 31, 117-132, 1993.

Varotsos, P., K. Alexopoulos, and M. Lazaridou, Latest aspects of earthquake prediction in Greece based on seismic electric signals, II, Tectonophysics, 224, 1-38, 1993.

Yoshino, T., Low-frequency seismogenic electromagnetic emissions as precursors to earthquakes and volcanic eruptions in Japan, J. Sci. Explor., 5, 121-144, 1991.

B. D. Enescu (e-mail: benescu@infp.infp.ro), D. Enescu, and A. P. Constantin 